\title{
Lipoprotein(a) is associated with necrotic core progression of non-culprit coronary lesions in statin-treated patients with angina pectoris
}

Tsuyoshi Nozue ${ }^{1 *}$, Shingo Yamamoto ${ }^{2}$, Shinichi Tohyama ${ }^{3}$, Kazuki Fukui ${ }^{4}$, Shigeo Umezawa ${ }^{5}$, Yuko Onishi', Tomoyuki Kunishima ${ }^{6}$, Akira Sato ${ }^{7}$, Toshihiro Nozato ${ }^{8}$, Shogo Miyake ${ }^{9}$, Youichi Takeyama $^{10}$, Yoshihiro Morino ${ }^{11}$, Takao Yamauchi ${ }^{12}$, Toshiya Muramatsu ${ }^{13}$, Kiyoshi Hibi ${ }^{14}$, Mitsuyasu Terashima ${ }^{15}$ and Ichiro Michishita ${ }^{1}$

\begin{abstract}
Background: Statin therapy results in regression and stabilization of coronary artery plaques, and reduces the incidence of coronary artery disease. However, statin therapy does not effectively halt the accumulation of necrotic core in all patients. The purpose of the present study was to identify the predictors associated with necrotic core progression during statin therapy.

Methods: Coronary atherosclerosis in non-culprit lesions was evaluated using virtual histology intravascular ultrasound at baseline and 8 months after statin therapy. One hundred nineteen patients were divided into 2 groups based on necrotic core progression or regression during an 8-month follow-up period.
\end{abstract}

Results: Patients with necrotic core progression had higher serum lipoprotein(a) [Lp(a)] levels than patients with regression at baseline (16 mg/dL vs. $12 \mathrm{mg} / \mathrm{dL}, \mathrm{p}=0.02)$ and at the 8-month follow-up (17 mg/dL vs. $10 \mathrm{mg} / \mathrm{dL}$, $p=0.006)$. Patients with necrotic core progression had a higher fibro-fatty plaque volume $\left(1.28 \mathrm{~mm}^{3} / \mathrm{mm}^{3}\right.$. $\left.0.73 \mathrm{~mm}^{3} / \mathrm{mm}, p=0.002\right)$, and less necrotic core $\left(0.56 \mathrm{~mm}^{3} / \mathrm{mm}\right.$ vs. $\left.1.04 \mathrm{~mm}^{3} / \mathrm{mm}, p<0.0001\right)$ and dense calcium $\left(0.35 \mathrm{~mm}^{3} / \mathrm{mm}\right.$ vs. $\left.0.56 \mathrm{~mm}^{3} / \mathrm{mm}, \mathrm{p}=0.006\right)$ plaque volumes at baseline than patients with regression. Multivariate logistic regression analysis showed that $L p(a)$ was a significant independent predictor associated with necrotic core progression during statin therapy (odds ratio [OR]: 3.514; 95\% confidence interval [Cl]: 1.338-9.228; $\mathrm{p}=0.01$ ).

Conclusions: Serum $\operatorname{Lp}(\mathrm{a})$ is independently associated with necrotic core progression in statin-treated patients with angina pectoris.

Keywords: Lipoprotein (a), Necrotic core, Statin, Virtual histology intravascular ultrasound

\section{Background}

Intensive lipid-lowering therapy with statins reduces the risk of coronary events [1]. Although the mechanisms by which statins provide cardiovascular benefits are not clearly understood, regression and stabilization of coronary artery plaques are presumed to play important roles in this effect $[2,3]$. Virtual histology $(\mathrm{VH})$-intravascular ultrasound (IVUS) uses spectral analysis of radiofrequency ultrasound backscatter signals, which allows the identification of 4 different types of atherosclerotic

\footnotetext{
* Correspondence: nozue2493@yahoo.co.jp

'Division of Cardiology, Department of Internal Medicine, Yokohama Sakae Kyosai Hospital, 132 Katsura-cho, Sakae-ku, Yokohama 247-8581, Japan Full list of author information is available at the end of the article
}

plaque components: fibrous, fibro-fatty, necrotic core, and dense calcium [4]. The rupture of a thin fibrous cap over the necrotic core followed by thrombus formation is the most prevalent cause of acute coronary syndrome [5]. Increasing necrotic core size is associated with plaque instability, and its volume is also associated with distal embolization after percutaneous coronary intervention (PCI) [6]. Statin therapy changes the composition of coronary artery plaques evaluated by using VH-IVUS [7-10]; however, the accumulation of necrotic core could not be halted with statin therapy in all patients. Therefore, in the present study, we compared clinical characteristics, serum lipid profiles, and grayscale and VH-IVUS parameters between patients with 
necrotic core progression and those with regression to identify predictors associated with necrotic core progression during statin therapy.

\section{Methods}

\section{Patients and study design}

The present study is a post-hoc subanalysis of the Treatment With Statin on Atheroma Regression Evaluated by Intravascular Ultrasound With Virtual Histology (TRUTH) trial. The TRUTH study was a prospective, open-labeled, randomized, multicenter trial performed at 11 Japanese centers to evaluate the effects of 8 months of treatment with pitavastatin versus pravastatin on coronary atherosclerosis using VH-IVUS [7]. Briefly, 164 patients with angina pectoris were randomized to either pitavastatin $(4 \mathrm{mg} /$ day, intensive lipid-lowering) or pravastatin $(20 \mathrm{mg} /$ day, moderate lipid-lowering) therapy after successful PCI performed under VH-IVUS guidance. None of the participants were taking a statin or other lipid-lowering drugs at the time of study enrollment. Follow-up IVUS examination was performed after 8 months of statin therapy.

The patients were included in the present study if they had measurable IVUS-detected lesions at both enrollment and the 8-month follow-up. Forty-five patients were excluded because of the following reason: withdrew consent in 3 patients, lost to follow-up in 7 patients, IVUS images were not obtained or not analyzable in 28 patients, and adverse events in 7 patients [7]. A total of 119 patients were divided into 2 groups: necrotic core progression or regression. An instance of necrotic core progression was defined as necrotic core volume at follow-up - necrotic core volume at baseline $\geq 0$. Necrotic core regression was defined as necrotic core volume at follow-up - necrotic core volume at baseline $<0$.

The TRUTH study was conducted in accordance with the Declaration of Helsinki and with the approval of the ethical committees of the 11 participating institutions. Each patient enrolled in the study provided written informed consent.

\section{IVUS examination and analysis}

The details of the IVUS procedure have been documented elsewhere [7]. Briefly, after PCI of the culprit lesion, angiographic lesions that showed no significant stenosis on the coronary angiogram (diameter stenosis $<50 \%$ ) were examined using IVUS. An IVUS catheter (Eagle Eye Gold; Volcano Corporation, San Diego, California) was used, and a motorized pullback device was used to withdraw the transducer at $0.5 \mathrm{~mm} / \mathrm{s}$. During pullback, grayscale IVUS was recorded, and raw radiofrequency data were captured at the top of the $\mathrm{R}$ wave using a commercially available IVUS console (IVG3; Volcano Corporation). After 8 months of statin therapy, the IVUS examination was repeated in the same coronary artery, using the same type of IVUS catheter that had been used at baseline.

All baseline and follow-up IVUS core laboratory analyses were performed by an independent and experienced investigator (M.T.) in a blinded manner. Before IVUS analysis, baseline and follow-up IVUS images were reviewed side-by-side on a display, and the distal and proximal ends of the target segment were identified on the basis of the presence of reproducible anatomical landmarks such as the side branch, vein, and stent edge. Plaques close to the PCI site $(<5 \mathrm{~mm})$ were excluded because mechanical interventions affected atheroma measurements. Quantitative IVUS grayscale analysis was performed according to the guidelines of the American College of Cardiology and European Society of Cardiology [11]. Manual contour detection of the lumen and external elastic membrane (EEM) was performed for each frame. The EEM volume and lumen volume were calculated, and difference between the 2 values was defined as plaque volume. All volumetric data were divided by lesion length to obtain a volume index. VH-IVUS data analysis was based on calculation of grayscale border contour, and relative and absolute amounts of different coronary artery plaque components were measured using IVUSLab version 2.2 (Volcano Corporation). Fibrous tissue was marked in green, fibro-fatty in yellow, dense calcium in white, and necrotic core in red on the VH-IVUS image [4].

\section{Blood sampling and measurement of blood parameters}

Blood samples were obtained after an overnight fast at baseline and at the 8-month follow-up. The levels of serum lipid and high-sensitivity C-reactive protein (hs-CRP) were measured at a central clinical laboratory (SRL Inc., Tokyo). Serum total cholesterol, low-density lipoprotein cholesterol (LDL-C), high-density lipoprotein cholesterol (HDL-C), and triglycerides levels were measured by standard enzymatic methods. Serum oxidized low-density lipoprotein (LDL) levels were measured by an enzyme immunoassay [12]. Serum lipoprotein(a) [Lp (a)] levels were measured by a latex agglutination turbidimetric immunoassay using the commercially available Lp(a)-LATEX (Sekisui Medical Co., Ltd., Tokyo) with an autoanalyzer (JCA-BM8040; JEOL Ltd., Tokyo). $\mathrm{Lp}$ (a) particles vary widely in size, with the size heterogeneity related primarily to the different sizes of the apo(a) isoform [13]; however, this method is not affected by apo(a) isoform variation [14]. The intraand interassay coefficients of variation of $\mathrm{Lp}(\mathrm{a})$ were $<5.0 \%$, respectively. Serum small dense LDL levels were measured by a homogeneous assay (Denka Seiken Co., Ltd., Tokyo) [15]. 


\section{Statistical analysis}

Statistical analysis was performed using StatView version 5.0 (SAS Institute, Cary, North Carolina). Results are expressed as mean $\pm \mathrm{SD}$, or as median (range). Differences in continuous variables between the 2 groups were compared using Student's unpaired $t$ tests when variables showed a normal distribution, and Mann-Whitney $\mathrm{U}$ tests when the variables were not normally distributed. Categorical variables between the 2 groups were compared using chi-square tests or Fisher's exact tests. Univariate and multivariate logistic regression analyses were performed to assess predictors associated with necrotic core progression during statin therapy. The variables with a $\mathrm{p}$ value $<0.1$ on univariate analysis were entered into multivariate models. $\mathrm{Lp}(\mathrm{a})$ and hs-CRP concentrations were converted to the logarithm for univariate and multivariate logistic regression analyses. Statistical significance was set at $\mathrm{p}<0.05$.

\section{Results}

Patients' characteristics and laboratory results

The baseline characteristics of the subjects are listed in Table 1. Seventy-four patients (62\%) were categorized as having necrotic core progression and the remaining 45 (38\%) as having regression. There were no significant differences in age, gender, frequency of hypertension and diabetes mellitus, or medications between the 2 groups. However, frequencies of pitavastatin treatment (55\% vs. $38 \%, \mathrm{p}=0.06)$ and unstable angina pectoris $(36 \%$ vs. $20 \%, p=0.05)$ tended to be higher in patients with necrotic core progression.

Risk factor control at baseline and at the 8-month follow-up is shown in Table 2. Serum levels of LDL-C, HDL-C, hs-CRP, and small dense LDL, at baseline and at the 8-month follow-up, did not differ between the 2 groups. However, patients with necrotic core progression had higher serum Lp(a) levels than patients with

Table 1 Baseline characteristics of subjects

\begin{tabular}{|c|c|c|c|}
\hline & $\begin{array}{c}\text { NC progression } \\
\quad(n=74)\end{array}$ & $\begin{array}{c}\text { NC regression } \\
\quad(n=45)\end{array}$ & $p$ value \\
\hline Age (years) & $66 \pm 10$ & $67 \pm 10$ & 0.56 \\
\hline Men & $63(85 \%)$ & $36(80 \%)$ & 0.47 \\
\hline Body mass index $\left(\mathrm{kg} / \mathrm{m}^{2}\right)$ & $24.7 \pm 3.7$ & $24.0 \pm 2.8$ & 0.28 \\
\hline Treatment allocation & & & 0.06 \\
\hline Pitavastatin & $41(55 \%)$ & $17(38 \%)$ & \\
\hline Pravastatin & $33(45 \%)$ & $28(62 \%)$ & \\
\hline Status of coronary artery desease & & & 0.05 \\
\hline Stable angina pectoris & $47(64 \%)$ & $36(80 \%)$ & \\
\hline Unstable angina pectoris & $27(36 \%)$ & $9(20 \%)$ & \\
\hline Target coronary artery & & & 0.51 \\
\hline Left anterior desending & $41(55 \%)$ & $26(58 \%)$ & \\
\hline Left circumflex & $2(3 \%)$ & $3(7 \%)$ & \\
\hline Right & $31(42 \%)$ & $16(36 \%)$ & \\
\hline Type of stent & & & 0.3 \\
\hline Bare metal stent & $15(20 \%)$ & $5(11 \%)$ & \\
\hline Drug-eluting stent & $59(80 \%)$ & $40(89 \%)$ & \\
\hline Hypertension & $44(59 \%)$ & $31(69 \%)$ & 0.3 \\
\hline Diabetes mellitus & $30(41 \%)$ & $20(44 \%)$ & 0.68 \\
\hline \multicolumn{4}{|l|}{ Medications } \\
\hline Aspirin & $72(97 \%)$ & $45(100 \%)$ & 0.7 \\
\hline Thienopyridines & 73 (99\%) & $45(100 \%)$ & $>0.99$ \\
\hline ACE-Is or ARBS & $37(50 \%)$ & $24(53 \%)$ & 0.72 \\
\hline$\beta$ blockers & $8(11 \%)$ & $5(11 \%)$ & $>0.99$ \\
\hline Calcium channel blockers & $35(47 \%)$ & $25(56 \%)$ & 0.38 \\
\hline Insulin & $5(7 \%)$ & $6(13 \%)$ & 0.38 \\
\hline Follow-up duration (days) & $224 \pm 34$ & $231 \pm 41$ & 0.31 \\
\hline
\end{tabular}

Data are expressed as mean \pm SD or as number (percentage).

NC, necrotic core; ACE-Is, angiotensin-converting enzyme inhibitors; ARBs, angiotensin reporter blockers. 
Table 2 Risk factor control at baseline and at the 8-month follow-up

\begin{tabular}{|c|c|c|c|c|c|c|}
\hline & \multicolumn{3}{|c|}{ Baseline } & \multicolumn{3}{|c|}{ 8-month follow-up } \\
\hline & $\begin{array}{l}\text { NC progression } \\
\quad(n=74)\end{array}$ & $\begin{array}{l}\text { NC regression } \\
\quad(n=45)\end{array}$ & $p$ value & $\begin{array}{l}\text { NC progression } \\
\quad(n=74)\end{array}$ & $\begin{array}{l}\text { NC regression } \\
\quad(n=45)\end{array}$ & $p$ value \\
\hline $\mathrm{TC}(\mathrm{mg} / \mathrm{dL})$ & $208 \pm 35$ & $200 \pm 37$ & 0.22 & $159 \pm 26$ & $157 \pm 32$ & 0.68 \\
\hline$\%$ change & & & & $-22 \pm 12$ & $-21 \pm 13$ & 0.46 \\
\hline LDL-C (mg/dL) & $133 \pm 31$ & $129 \pm 32$ & 0.48 & $85 \pm 22$ & $85 \pm 29$ & 0.91 \\
\hline$\%$ change & & & & $-36 \pm 14$ & $-34 \pm 18$ & 0.48 \\
\hline Triglycerides (mg/dL) & $130 \pm 71$ & $132 \pm 55$ & 0.92 & $122 \pm 67$ & $108 \pm 57$ & 0.26 \\
\hline$\%$ change & & & & $1 \pm 46$ & $-14 \pm 37$ & 0.07 \\
\hline $\mathrm{HDL}-\mathrm{C}(\mathrm{mg} / \mathrm{dL})$ & $47 \pm 12$ & $45 \pm 10$ & 0.3 & $51 \pm 13$ & $51 \pm 13$ & 0.86 \\
\hline$\%$ change & & & & $10 \pm 25$ & $13 \pm 23$ & 0.54 \\
\hline $\mathrm{Hs}-\mathrm{CRP}(\mathrm{ng} / \mathrm{mL})$ & 4750 (103 to 88900$)$ & 3300 (54 to 76800$)$ & 0.57 & 654 (52 to 26200) & 582 (78 to 23300) & 0.98 \\
\hline$\%$ change & & & & $-40 \pm 113$ & $-45 \pm 73$ & 0.79 \\
\hline Small dense LDL (mg/dL) & $26 \pm 14$ & $26 \pm 13$ & 0.96 & $18 \pm 8$ & $20 \pm 10$ & 0.45 \\
\hline$\%$ change & & & & $-15 \pm 52$ & $-19 \pm 32$ & 0.76 \\
\hline Oxidized LDL (U/mL) & $13 \pm 9$ & $10 \pm 7$ & 0.08 & $11 \pm 8$ & $9 \pm 9$ & 0.18 \\
\hline$\%$ change & & & & $-3 \pm 43$ & $11 \pm 166$ & 0.52 \\
\hline Lipoprotein(a) (mg/dL) & 16 (3 to 47 ) & $12(1$ to 43$)$ & 0.02 & 17 (1 to 118$)$ & $10(1$ to 60$)$ & 0.006 \\
\hline$\%$ change & & & & $26 \pm 53$ & $12 \pm 49$ & 0.16 \\
\hline
\end{tabular}

Data are expressed as mean \pm SD or median (range).

NC, necrotic core; TC, total cholesterol; LDL-C, low-density lipoprotein cholesterol; HDL-C, high-density lipoprotein cholesterol; Hs-CRP, high-sensitivity C-reactive protein; LDL, low density lipoprotein.

Table 3 Parameters evaluated using grayscale and virtual histology intravascular ultrasound

\begin{tabular}{|c|c|c|c|c|c|c|}
\hline & \multicolumn{3}{|c|}{ Baseline } & \multicolumn{3}{|c|}{ 8-month follow-up } \\
\hline & $\begin{array}{l}\text { NC progression } \\
\quad(n=74)\end{array}$ & $\begin{array}{l}\text { NC regression } \\
\quad(n=45)\end{array}$ & $p$ value & $\begin{array}{l}\text { NC progression } \\
\quad(n=74)\end{array}$ & $\begin{array}{l}\text { NC regression } \\
\quad(n=45)\end{array}$ & $p$ value \\
\hline EEM volume index $\left(\mathrm{mm}^{3} / \mathrm{mm}\right)$ & $16.45 \pm 5.59$ & $16.18 \pm 4.83$ & 0.79 & $16.09 \pm 5.52$ & $16.11 \pm 5.02$ & 0.98 \\
\hline$\%$ change & & & & $-2.1 \pm 5.1$ & $-0.5 \pm 6.4$ & 0.12 \\
\hline Plaque volume index $\left(\mathrm{mm}^{3} / \mathrm{mm}\right)$ & $9.11 \pm 3.62$ & $8.66 \pm 2.73$ & 0.47 & $8.91 \pm 3.37$ & $8.58 \pm 2.96$ & 0.58 \\
\hline$\%$ change & & & & $-1.4 \pm 8.5$ & $-1.0 \pm 10.1$ & 0.84 \\
\hline Lumen volume index $\left(\mathrm{mm}^{3} / \mathrm{mm}\right)$ & $7.34 \pm 2.58$ & $7.52 \pm 2.66$ & 0.71 & $7.17 \pm 2.62$ & $7.54 \pm 2.72$ & 0.47 \\
\hline$\%$ change & & & & $-1.9 \pm 11.2$ & $0.5 \pm 12.5$ & 0.28 \\
\hline Percent atheroma volume (\%) & $55.1 \pm 7.2$ & $53.6 \pm 6.6$ & 0.27 & $55.3 \pm 6.5$ & $53.3 \pm 7.5$ & 0.12 \\
\hline Nominal change (\%) & & & & $0.2 \pm 4.0$ & $-0.4 \pm 4.4$ & 0.47 \\
\hline Fibrous volume index $\left(\mathrm{mm}^{3} / \mathrm{mm}\right)$ & $3.50 \pm 2.01$ & $2.95 \pm 1.44$ & 0.11 & $3.17 \pm 1.74$ & $3.08 \pm 1.52$ & 0.78 \\
\hline Change $\left(\mathrm{mm}^{3} / \mathrm{mm}\right)$ & & & & $-0.34 \pm 0.74$ & $0.13 \pm 0.84$ & 0.002 \\
\hline FF volume index $\left(\mathrm{mm}^{3} / \mathrm{mm}\right)$ & $1.28 \pm 1.08$ & $0.73 \pm 0.57$ & 0.002 & $0.77 \pm 0.68$ & $0.91 \pm 0.83$ & 0.33 \\
\hline Change $\left(\mathrm{mm}^{3} / \mathrm{mm}\right)$ & & & & $-0.51 \pm 0.67$ & $0.18 \pm 0.53$ & $<0.0001$ \\
\hline $\mathrm{NC}$ volume index $\left(\mathrm{mm}^{3} / \mathrm{mm}\right)$ & $0.56 \pm 0.41$ & $1.04 \pm 0.64$ & $<0.0001$ & $0.99 \pm 0.63$ & $0.67 \pm 0.44$ & 0.003 \\
\hline Change $\left(\mathrm{mm}^{3} / \mathrm{mm}\right)$ & & & & $0.43 \pm 0.40$ & $-0.37 \pm 0.39$ & $<0.0001$ \\
\hline DC volume index $\left(\mathrm{mm}^{3} / \mathrm{mm}\right)$ & $0.35 \pm 0.33$ & $0.56 \pm 0.50$ & 0.006 & $0.55 \pm 0.48$ & $0.54 \pm 0.54$ & 0.92 \\
\hline Change $\left(\mathrm{mm}^{3} / \mathrm{mm}\right)$ & & & & $0.20 \pm 0.27$ & $-0.02 \pm 0.31$ & $<0.0001$ \\
\hline Average length (mm) & $24.7 \pm 15.9$ & $24.3 \pm 13.3$ & 0.88 & $24.9 \pm 16.1$ & $24.2 \pm 13.1$ & 0.81 \\
\hline
\end{tabular}

Data are expressed as mean \pm SD.

NC, necrotic core; EEM, external elastic membrane; FF, fibro-fatty; DC, dense calcium. 
regression at baseline $(16 \mathrm{mg} / \mathrm{dL}$ vs. $12 \mathrm{mg} / \mathrm{dL}, \mathrm{p}=0.02)$ and at the 8-month follow-up $(17 \mathrm{mg} / \mathrm{dL}$ vs. $10 \mathrm{mg} / \mathrm{dL}$, $\mathrm{p}=0.006$ ). Furthermore, oxidized LDL levels at baseline tended to be higher in patients with necrotic core progression $(13 \mathrm{U} / \mathrm{mL}$ vs. $10 \mathrm{U} / \mathrm{mL}, \mathrm{p}=0.08)$. Percentage changes in these parameters did not differ between the 2 groups.

\section{Grayscale and VH-IVUS analysis}

The parameters evaluated using grayscale and VH-IVUS are listed in Table 3. The EEM volume index, plaque volume index, and lumen volume index did not differ between the 2 groups. No significant differences were observed in percentage changes in these parameters. However, patients with necrotic core progression had higher fibro-fatty plaque volume and less necrotic core and dense calcium plaque volumes at baseline than patients with regression. Furthermore, changes in each of the 4 plaque component significantly differed between the 2 groups.

\section{Predictors of necrotic core progression}

Univariate logistic regression analyses showed that Lp(a) was significantly associated with necrotic core progression during statin therapy whereas pravastatin use or unstable angina pectoris trended (Table 4). Multivariate logistic regression analysis showed that $\mathrm{Lp}(\mathrm{a})$ was a significant independent predictor associated with necrotic core progression during statin therapy (odds ratio [OR]: 3.514; 95\% confidence interval [CI]: 1.338-9.228; $\mathrm{p}=0.01)$.
The representative IVUS images are shown in Figures 1 and 2. Figure 1 shows IVUS images of a 71-year-old male patient with unstable angina pectoris whose baseline serum Lp(a) level was $47 \mathrm{mg} / \mathrm{dL}$. A greater increase in the necrotic core area was observed at the 8-month follow-up. Figure 2 shows IVUS images of a 78-year-old male patient with stable angina pectoris whose baseline serum Lp(a) level was $3 \mathrm{mg} / \mathrm{dL}$. A greater reduction of the necrotic core area was observed at the 8-month follow-up.

\section{Discussion}

The major findings of the present study are as follows: (1) $\mathrm{Lp}$ (a) was a significant independent predictor associated with necrotic core progression during statin therapy; (2) patients with necrotic core progression had higher fibro-fatty plaque volume and less necrotic core and dense calcium plaque volumes at baseline than patients with regression; and (3) $62 \%$ of patients treated with statin showed necrotic core progression during an 8-month follow-up period.

$\mathrm{Lp}(\mathrm{a})$ is a recognized risk factor for cardiovascular disease $[16,17]$. Mechanisms that account for the association of $\mathrm{Lp}$ (a) with cardiovascular disease have been considered to be its structural similarity to plasminogen which could cause competition with plasminogen activators [18]; intraluminal thrombus formation may also cause a proliferative response of the vascular wall. A recent report supports its role as a prothrombotic factor in that $L p(a)$ appears to be significantly associated with carotid artery occlusion but not plaque size [19].

Table 4 Predictors of necrotic core progression

\begin{tabular}{|c|c|c|c|c|c|c|}
\hline & \multicolumn{3}{|c|}{ Univariate } & \multicolumn{3}{|c|}{ Multivariate } \\
\hline & OR & $95 \% \mathrm{Cl}$ & $p$ value & OR & $95 \% \mathrm{Cl}$ & $p$ value \\
\hline Age & 0.989 & $0.953-1.026$ & 0.56 & & & \\
\hline Male gender & 1.432 & $0.542-3.783$ & 0.47 & & & \\
\hline Smoking & 0.642 & $0.266-1.548$ & 0.32 & & & \\
\hline Pravastatin & 0.489 & $0.229-1.042$ & 0.06 & 0.525 & $0.233-1.184$ & 0.12 \\
\hline Unstable angina pectoris & 2.298 & $0.962-5.487$ & 0.06 & 1.934 & $0.768-4.869$ & 0.16 \\
\hline Hypertension & 0.662 & $0.303-1.450$ & 0.3 & & & \\
\hline Diabetes mellitus & 0.852 & $0.403-1.803$ & 0.68 & & & \\
\hline $\mathrm{TC}$ & 1.003 & $0.990-1.016$ & 0.68 & & & \\
\hline LDL-C & 0.999 & $0.984-1.014$ & 0.91 & & & \\
\hline Triglycerides & 1.004 & $0.997-1.010$ & 0.26 & & & \\
\hline $\mathrm{HDL}-\mathrm{C}$ & 1.003 & $0.973-1.033$ & 0.86 & & & \\
\hline Log (hs-CRP) & 0.939 & $0.501-1.757$ & 0.84 & & & \\
\hline Small dense LDL & 0.983 & $0.941-1.027$ & 0.45 & & & \\
\hline Oxidized LDL & 1.040 & $0.979-1.103$ & 0.2 & & & \\
\hline Log [lipoprotein(a)] & 3.664 & $1.423-9.435$ & 0.01 & 3.514 & $1.338-9.228$ & 0.01 \\
\hline
\end{tabular}

OR, odds ratio; $\mathrm{Cl}$, confidence interval; TC, total cholesterol; LDL-C, low density lipoprotein cholesterol; HDL-C, high-density lipoprotein cholesterol; hs-CRP, high-sensitivity C-reactive protein, LDL, low-density lipoprotein. 

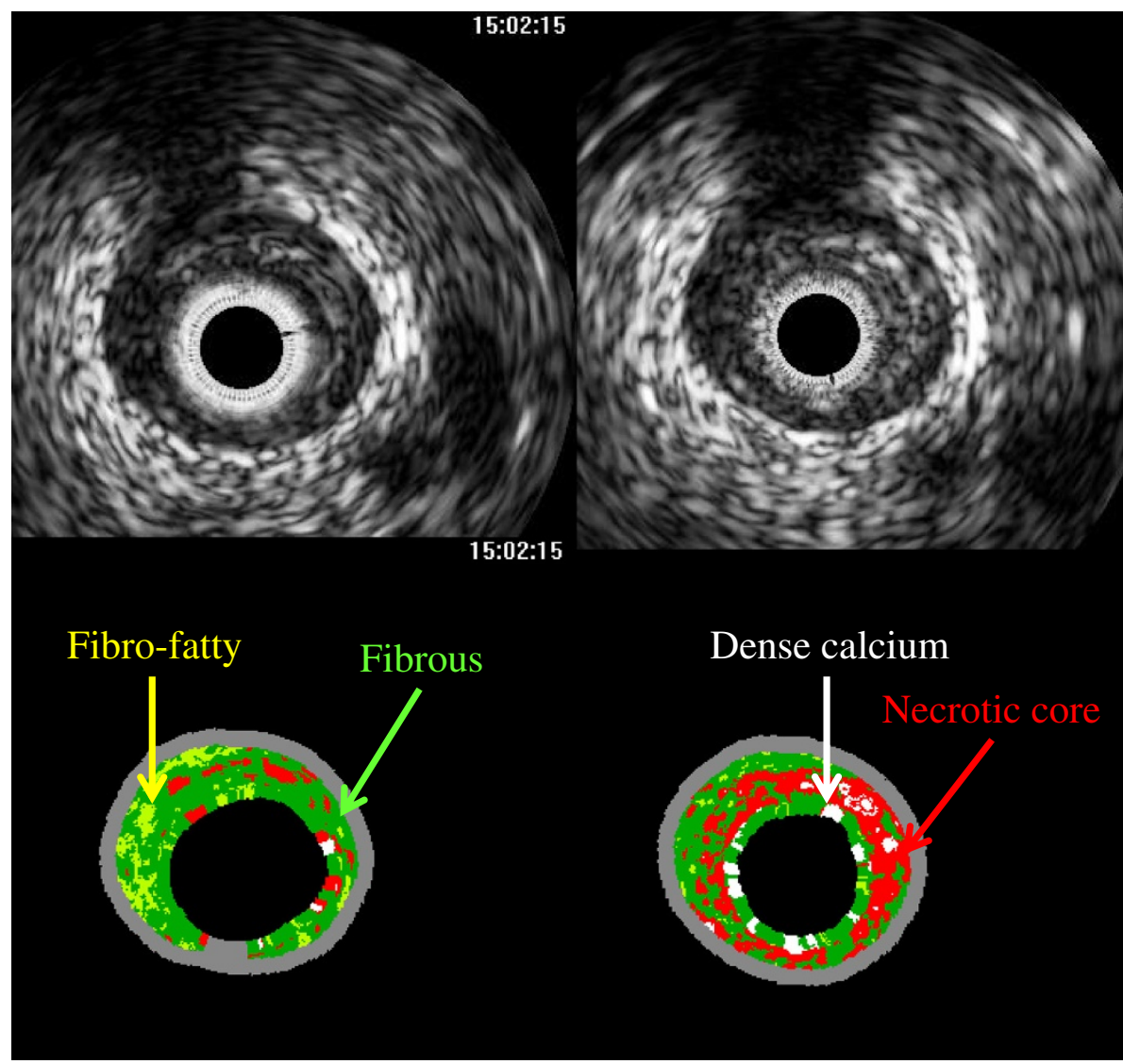

Baseline

8-month follow-up

Figure 1 Representative intravascular ultrasound images of necrotic core progression. Fibrous areas were marked in green, fibro-fatty in yellow, dense calcium in white, and necrotic core in red on the virtual histology intravascular ultrasound image. This case was a 71-year-old male patient with unstable angina pectoris treated with pravastatin. His baseline serum lipoprotein(a) level was $47 \mathrm{mg} / \mathrm{dL}$. A greater increase in the necrotic core area was observed at the 8-month follow-up.

However, Helgadottir et al. reported a stronger association of $\mathrm{Lp}(\mathrm{a})$ with atherosclerosis than with thrombosis [20]. Furthermore, $\mathrm{Lp}(\mathrm{a})$ is associated with plaque progression, as indirectly assessed based on lumen changes on angiography $[21,22]$. Although there are few data directly demonstrating a relationship between serum $L p(a)$ and coronary atherosclerosis, serum $\operatorname{Lp}(\mathrm{a})$ is an independent predictor of plaque progression [23]. A consensus paper issued $\mathrm{Lp}(\mathrm{a})$ as a causal risk factor for cardiovascular disease, and recommended screening for $\mathrm{Lp}(\mathrm{a})$ in patients judged to be at high risk for future cardiovascular disease [24]. Indeed, $\mathrm{Lp}(\mathrm{a})$ is associated with future cardiovascular events [25] and an adverse prognosis [26]. Our study, therefore, supports the likelihood that $\mathrm{Lp}(\mathrm{a})$ is a good predictor of future cardiovascular events, because serum $L p(a)$ is associated with necrotic core progression during statin therapy.

The underlying mechanisms by which $\mathrm{Lp}$ (a) contributes to the pathogenesis of atherosclerosis are not fully understood [27]. The pathophysiologic role of $\mathrm{Lp}(\mathrm{a})$ in atherosclerotic disease progression is explained by the accumulation of $\mathrm{Lp}(\mathrm{a})$ in the vessel wall, and its ability to promote cholesterol accumulation in macrophages forming foam cells and subsequent fatty streaks $[28,29]$. Kiechl et al. reported a strong correlation between circulating $L p(a)$ levels and oxidized phospholipid/apolipoprotein $B$ complex which suggested that $\mathrm{Lp}(\mathrm{a})$ transported the proinflammatory burden of oxidized phos pholipids [30]. The atherogenicity of $L p(a)$ may be mediated in part by associated proinflammatory oxidized phospholipids, and is associated with angiographically documented coronary artery disease [31]. A recent study has documented that $\mathrm{Lp}(\mathrm{a})$ and oxidized phospholipids mediated macrophage apoptosis [32]. Since macrophage apoptosis is a key component of plaque vulnerability, these phenomena may lead to necrotic core progression as observed in this study. Thus, Lp(a) may mediate antifibrinolytic, proinflammatory, and proapoptotic effects, including those potentiated by its content of oxidized phospholipids [27]. 


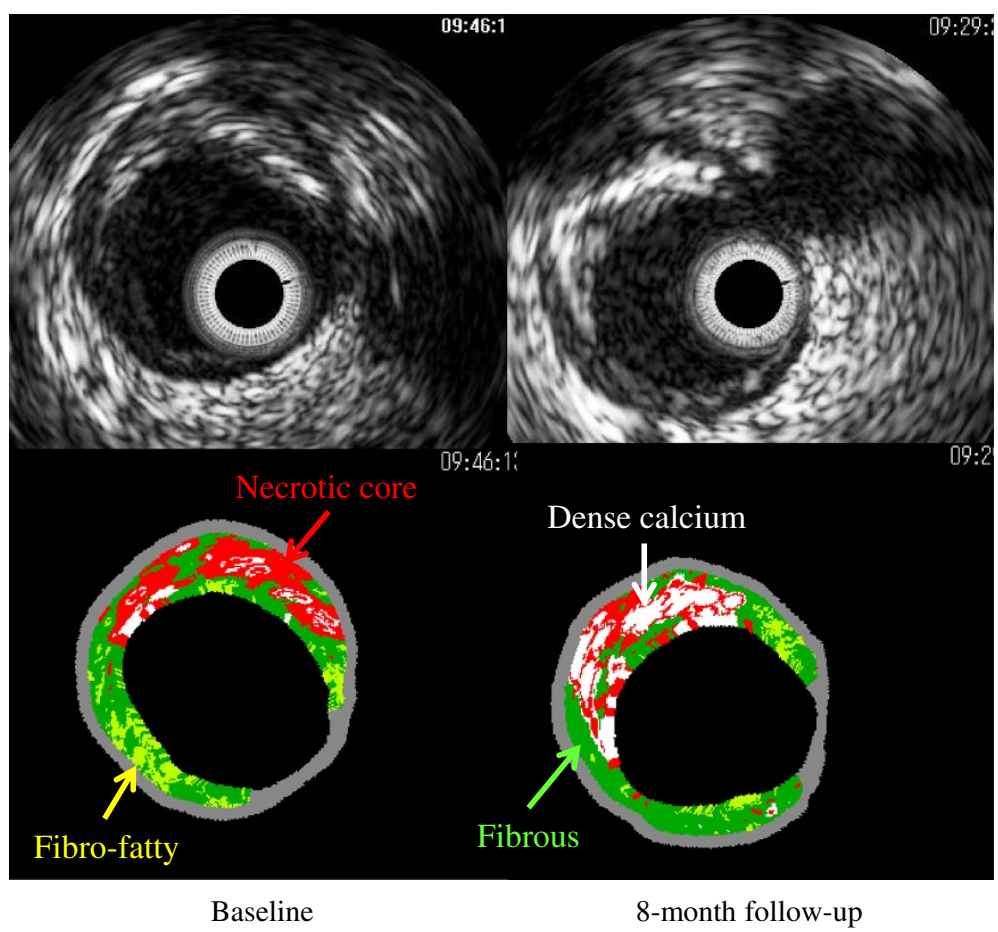

Figure 2 Representative intravascular ultrasound images of necrotic core regression. This case was a 78-year-old male patient with stable angina pectoris treated with pravastatin. His baseline serum lipoprotein(a) level was $3 \mathrm{mg} / \mathrm{dL}$. A greater reduction of the necrotic core area was observed at the 8-month follow-up.

There is no consensus regarding the effects of statins on the necrotic core component [7-10]. Thus, the accumulation of necrotic core could not be halted with statin therapy in all patients. These differences may have occurred because of lipophilic and hydrophilic statins because lipophilic pitavastatin promotes oxidant stressinduced apoptosis of vascular smooth muscle cells, whereas hydrophilic pravastatin does not $[7,33]$. In addition, statin therapy could not halt the increase in plaque vulnerability in patients with unstable angina pectoris [34]. The differences of types of statin and subject population could account for these discrepancies. Indeed, pitavastatin use and unstable angina pectoris was associated with necrotic core progression on univariate regression analyses.

Additional important results of the present study were that $62 \%$ of patients treated with statin had necrotic core progression during an 8-month follow-up period and this may associate with future cardiovascular events as previously reported [35]. In addition, plaques with greater fibro-fatty and less necrotic core component were prone to necrotic core progression during statin therapy. These results are consistent with previous reports that the fibro-fatty component is a reversible step of atherosclerosis $[7,8,36]$. As observed in this study, Lp (a) concentration is not influenced by statin therapy [37]. However, $\operatorname{Lp}(\mathrm{a})$ is also the dominant risk factor for the severity and progression of coronary artery disease in patients treated with statins [38], our results support these reports. Intensive lipid-lowering therapy with statins reduces the risk of coronary events [1]; however, there is a residual risk. This implies a role for $L p(a)$ in being one of the potential etiologies for the presence of residual cardiovascular risk, and increases the priority for investigation of $\mathrm{Lp}(\mathrm{a})$ as a potential therapeutic target. Niacin was able to reduce serum Lp(a) levels $[39,40]$, and niacin added to simvastatin decreased carotid intima-media thickness [41], whereas no incremental clinical benefit was observed from the addition of niacin to statin therapy [42]. Further studies are necessary to investigate better therapeutic options in statintreated patients with high Lp(a) levels.

This study has several limitations. First, it was a posthoc subanalysis and the results of this study may be biased because all subjects were treated with statins. However, this study demonstrate that the residual risk of cardiovascular events during statin therapy can be explained in part by $\operatorname{Lp}(\mathrm{a})$. Second, although we excluded patients with angiographically apparent thrombi, an intramural thrombus might have influenced the study results. In addition, the IVUS examination was performed in only the non-culprit lesions in the culprit vessel. Mechanical interventions might have affected the atheroma measurement. Furthermore, although VH- 
IVUS is a promising new diagnostic tool for visual interpretation of plaque characterization, it is not a substitute for pathologic sampling. Nair et al. reported that dividing a plaque into 4 distinct tissue components was difficult because of the presence of amorphous overlapping zones [33]. Third, although $\mathrm{Lp}(\mathrm{a})$ appears to act an acute-phase reactant under some situation $[43,44]$, we could not analyze the subjects with stable and unstable angina pectoris separately because of statistical power. Finally, this study is limited by the relatively small number of patients.

\section{Conclusions}

Serum $L p(a)$ level is independently associated with necrotic core progression in statin-treated patients with angina pectoris. In particular, the data suggest considerable incremental value in using $\mathrm{Lp}(\mathrm{a})$ for predicting cardiovascular risk during statin therapy.

\section{Abbreviations \\ Cl: Confidence interval; EEM: External elastic membrane; HDL-C: High-density lipoprotein cholesterol; hs-CRP: High-sensitivity C-reactive protein; IVUS: Intravascular ultrasound; LDL: Low-density lipoprotein; LDL-C: Low-density lipoprotein cholesterol; Lp(a): Lipoprotein(a); OR: Odds ratio; PCl: Percutaneous coronary intervention; TRUTH: Treatment with statin on atheroma regression evaluated by intravascular ultrasound with virtual histology; VH: Virtual histology.}

\section{Competing interests}

The authors declare that they have no competing interests.

\section{Authors' contributions}

TN contributed to the study design, analysis and interpretation of data, and manuscript preparation. SY, ST, KF, SU, YO, TK, AS, TN, SM, YT, YM, TY and TM contributed to acquisition of data. $\mathrm{KH}$ contributed to the study design. MT contributed to the analysis of the data. IM contributed to the study design and managed the study. All authors read and approved the final manuscript.

\section{Author details}

'Division of Cardiology, Department of Internal Medicine, Yokohama Sakae Kyosai Hospital, 132 Katsura-cho, Sakae-ku, Yokohama 247-8581, Japan. ${ }^{2}$ Department of Cardiology, Tsurumi Nishiguchi Hospital, Yokohama, Japan. ${ }^{3}$ Department of Cardiology, Yokohama Seamen's Insurance Hospital, Yokohama, Japan. ${ }^{4}$ Department of Cardiology, Kanagawa Cardiovascular and Respiratory Center, Yokohama, Japan. ${ }^{5}$ Department of Cardiology, Hiratsuka Kyosai Hospital, Hiratsuka, Japan. ${ }^{6}$ Fourth Department of Internal Medicine, Mizonokuchi Hospital, Teikyo University School of Medicine, Kawasaki, Japan. ${ }^{7}$ Cardiovascular Center, Yokosuka Kyosai Hospital, Yokosuka, Japan.

${ }^{8}$ Department of Cardiology, National Hospital Organization, Disaster Medical Center, Tokyo, Japan. ${ }^{9}$ Department of Cardiology, Ebina General Hospital, Ebina, Japan. ${ }^{10}$ Division of Cardiology, Showa University Fujigaoka Rehabilitation Hospital, Yokohama, Japan. ${ }^{11}$ Department of Cardiology, Tokai University School of Medicine, Isehara, Japan. ${ }^{12}$ Department of Cardiology, Tokyo Women's Medical University, Tokyo, Japan. ${ }^{13}$ Department of Cardiology, Saiseikai Yokohama City Eastern Hospital, Yokohama, Japan. ${ }^{14}$ Division of Cardiology, Yokohama City University Medical Center, Yokohama, Japan. ${ }^{15}$ Cardiovascular Imaging Center, Toyohashi, Japan.

Received: 4 February 2014 Accepted: 18 March 2014 Published: 1 April 2014

\section{References}

1. Treating to New Targets (TNT) Investigators, LaRosa JC, Grundy SM, Waters DD, Shear C, Barter P, Fruchart JC, Gotto AM, Greten H, Kastelein JJ, Shepherd J, Wenger NK: Intensive lipid lowering with atorvastatin in patients with stable coronary disease. N Engl J Med 2005, 352:1425-1435.
2. Nicholls SJ, Hsu A, Wolski K, Hu B, Bayturan O, Lavoie A, Uno K, Tuzcu EM, Nissen SE: Intravascular ultrasound-derived measures of coronary atherosclerotic plaque burden and clinical outcome. J Am Coll Cardiol 2010, 55:2399-2407.

3. Aikawa M, Rabkin E, Sugiyama S, Voglic SJ, Fukumoto Y, Furukawa Y, Shiomi M, Schoen FJ, Libby P: An HMG-CoA reductase inhibitor, cerivastatin, suppresses growth of macrophages expressing matrix metalloproteinases and tissue factor in vivo and in vitro. Circulation 2001, 103:276-283.

4. Nair A, Kuban BD, Tuzcu EM, Schoenhagen P, Nissen SE, Vince DG: Coronary plaque classification with intravascular ultrasound radiofrequency data analysis. Circulation 2002, 106:2200-2206.

5. Libby $P$ : Current concepts of the pathogenesis of the acute coronary syndromes. Circulation 2001, 104:365-372.

6. Kawaguchi R, Oshima S, Jingu M, Tsurugaya H, Toyama T, Hoshizaki H, Taniguchi K: Usefulness of virtual histology intravascular ultrasound to predict distal embolization for ST-segment elevation myocardial infarction. J Am Coll Cardiol 2007, 50:1641-1646.

7. Nozue T, Yamamoto S, Tohyama S, Umezawa S, Kunishima T, Sato A, Miyake S, Takeyama Y, Morino Y, Yamauchi T, Muramatsu T, Hibi K, Sozu T, Terashima M, Michishita I: Statin treatment for coronary artery plaque composition based on intravascular ultrasound radiofrequency data analysis. Am Heart J 2012, 163:191-199.

8. Nasu K, Tsuchikane E, Katoh O, Tanaka N, Kimura M, Ehara M, Kinoshita Y, Matsubara T, Matsuo H, Asakura K, Asakura Y, Terashima M, Takayama T, Honye J, Hirayama A, Saito S, Suzuki T: Effect of fluvastatin on progression of coronary atherosclerotic plaque evaluated by virtual histology intravascular ultrasound. JACC Cardiovasc Interv 2009, 2:689-696.

9. Eshtehardi P, McDaniel MC, Dhawan SS, Binongo JN, Krishnan SK, Golub L, Corban MT, Raggi P, Quyyumi AA, Samady H: Effect of intensive atorvastatin therapy on coronary atherosclerosis progression, composition, arterial remodeling, and microvascular function. J Invasive Cardiol 2012, 24:522-529.

10. Hong MK, Park DW, Lee CW, Lee SW, Kim YH, Kang DH, Song JK, Kim JJ, Park SW, Park SJ: Effects of statin treatments on coronary plaques assessed by volumetric virtual histology intravascular ultrasound analysis. JACC CardiovasC Interv 2009, 2:679-688.

11. Mintz GS, Nissen SE, Anderson WD, Bailey SR, Erbel R, Fitzgerald PJ, Pinto FJ, Rosenfield K, Siegel RJ, Tuzcu EM, Yock PG: American college of cardiology clinical expert consensus document on standards for acquisition, measurement and reporting of Intravascular Ultrasound Studies (IVUS). a report of the American college of cardiology task force on clinical expert consensus documents. J Am Coll Cardiol 2001, 37:1478-1492.

12. Kohno H, Sueshige N, Oguri K, Izumidate H, Masunari T, Kawamura M, Itabe H, Takano T, Hasegawa A, Nagai R: Simple and practical sandwich-type enzyme immunoassay for human oxidatively modified low density lipoprotein using antioxidized phosphatidylcholine monoclonal antibody and antihuman apolipoprotein-B antibody. Clin Biochem 2000, 33:243-253.

13. Pfaffinger D, Schuelke J, Kim C, Fless GM, Scanu AM: Relationship between apo[a] isoforms and Lp[a] density in subjects with different apo[a] phenotype: a study before and after a fatty meal. J Lipid Res 1991, 32:679-683.

14. Gaw A, Gourlay CW, Brown EA, Bell MA: Evaluation of a new automated latex agglutination assay for lipoprotein(a): comparison with a manual ELISA. Clin Chim Acta 1997, 261:175-183.

15. Ito $Y$, Fujimura M, Ohta M, Hirano T: Development of a homogeneous assay for measurement of small dense LDL cholesterol. Clin Chem 2011, 57:57-65.

16. Cardiovascular Health Study Investigators, Ariyo AA, Thach C, Tracy R: Lp(a) lipoprotein, vascular disease, and mortality in the elderly. N Engl J Med 2003, 349:2108-2115.

17. Danesh J, Collins R, Peto R: Lipoprotein(a) and coronary heart disease Meta-analysis of prospective studies. Circulation 2000, 102:1082-1085.

18. Deb A, Caplice NM: Lipoprotein(a): new insights into mechanisms of atherogenesis and thrombosis. Clin Cardiol 2004, 27:258-264.

19. Spence JD, Koschinsky M: Mechanisms of lipoprotein(a) pathogenicity: prothrombotic, proatherosclerotic, or both? Arterioscler Thromb Vasc Biol 2012, 32:1550-1551.

20. Helgadottir A, Gretarsdottir S, Thorleifsson G, Holm H, Patel RS, Gudnason T, Jones GT, van Rij AM, Eapen DJ, Baas AF, Tregouet DA, Morange PE, Emmerich J, Lindblad B, Gottsäter A, Kiemeny LA, Lindholt JS, Sakalihasan N, Ferrell RE, Carey DJ, Elmore JR, Tsao PS, Grarup N, Jørgensen T, Witte DR, 
Hansen T, Pedersen O, Pola R, Gaetani E, Magnadottir HB, et al: Apolipoprotein(a) genetic sequence variants associated with systemic atherosclerosis and coronary atherosclerotic burden but not with venous thromboembolism. J Am Coll Cardiol 2012, 60:722-729.

21. Terres W, Tatsis E, Pfalzer B, Beil FU, Beisiegel U, Hamm CW: Rapid angiographic progression of coronary artery disease in patients with elevated lipoprotein(a). Circulation 1995, 91:948-950.

22. Nicholls SJ, Tang WH, Scoffone H, Brennan DM, Hartiala J, Allayee $H_{\text {, }}$ Hazen SL: Lipoprotein(a) levels and long-term cardiovascular risk in the contemporary era of statin therapy. J Lipid Res 2010, 51:3055-3061.

23. Hartmann M, von Birgelen C, Mintz GS, Stoel MG, Eggebrecht $H$, Wieneke $H$, Fahy M, Neumann T, van der Palen J, Louwerenburg HW, Verhorst PM, Erbel R: Relation between lipoprotein(a) and fibrinogen and serial intravascular ultrasound plaque progression in left main coronary arteries. J Am Coll Cardiol 2006, 48:446-452.

24. European Atherosclerosis Society Consensus Panel, Nordestgaard BG, Chapman MJ, Ray K, Borén J, Andreotti F, Watts GF, Ginsberg H, Amarenco P, Catapano A, Descamps OS, Fisher E, Kovanen PT, Kuivenhoven JA, Lesnik P, Masana L, Reiner Z, Taskinen MR, Tokgözoglu L, Tybjærg-Hansen A: Lipoprotein(a) as a cardiovascular risk factor: current status. Eur Heart J 2010, 31:2844-2853.

25. Nestel PJ, Barnes EH, Tonkin AM, Simes J, Fournier M, White HD, Colquhoun DM, Blankenberg S, Sullivan DR: Plasma lipoprotein(a) concentration predicts future coronary and cardiovascular events in patients with stable coronary heart disease. Arterioscler Thromb Vasc Biol 2013, 33:2902-2908

26. Kwon SW, Lee BK, Hong BK, Kim JY, Choi EY, Sung JM, Rhee JH, Park YM, Ma DW, Chung H, Mun HS, Lee SJ, Park JK, Min PK, Yoon YW, Rim SJ, Kwon HM: Prognostic significance of elevated lipoprotein(a) in coronary artery revascularization patients. Int J Cariol 2013, 167:1990-1994

27. Tsimikas S, Hall JL: Lipoprotein(a) as a potential causal genetic risk factor of cardiovascular disease: a rationale for increased efforts to understand its pathophysiology and develop targeted therapies. J Am Coll Cardiol 2012, 60:716-721.

28. Nielsen LB, Juul K, Nordestgaard BG: Increased degradation of lipoprotein (a) in atherosclerotic compared with nonlesioned aortic intima-inner media of rabbits: in vivo evidence that lipoprotein(a) may contribute to foam cell formation. Arterioscler Thromb Vasc Biol 1998, 18:641-649.

29. Maher VM, Brown BG: Lipoprotein (a) and coronary heart disease. Curr Opin Lipidol 1995, 6:229-235.

30. Kiechl S, Willeit J, Mayr M, Viehweider B, Oberhollenzer M, Kronenberg F, Wiedermann CJ, Oberthaler S, Xu Q, Witztum JL, Tsimikas S: Oxidized phospholipids, lipoprotein(a), lipoprotein-associated phospholipase A2 activity, and 10-year cardiovascular outcomes: prospective results from the Bruneck study. Arterioscler Thromb Vasc Biol 2007, 27:1788-1795.

31. Tsimikas S, Brilakis ES, Miller ER, McConnell JP, Lennon RJ, Kornman KS, Witztum JL, Berger PB: Oxidized phospholipids, Lp(a) lipoprotein, and coronary artery disease. N Engl J Med 2005, 353:46-57.

32. Seimon TA, Nadolski MJ, Liao X, Magallon J, Nguyen M, Feric NT, Koschinsky ML, Harkewicz R, Witztum JL, Tsimikas S, Golenbock D, Moore KJ, Tabas I: Atherogenic lipids and lipoproteins trigger CD36-TLR2-dependent apoptosis in macrophages undergoing endoplasmic reticulum stress. Cell Metab 2010, 12:467-482.

33. Nair A, Margolis MP, Kuban BD, Vince DG: Automated coronary plaque characterisation with intravascular ultrasound backscatter: ex vivo validation. Eurolntervention 2007, 3:113-120.

34. TRUTH Investigators, Nozue T, Yamamoto S, Tohyama S, Fukui K, Umezawa S, Onishi Y, Kunishima T, Sato A, Nozato T, Miyake S, Takeyama Y, Morino Y, Yamauchi T, Muramatsu T, Hibi K, Terashima M, Michishita I: Comparison of change in coronary atherosclerosis in patients with stable versus unstable angina pectoris receiving statin therapy (from the Treatment With Statin on Atheroma Regression Evaluated by Intravascular Ultrasound With Virtual Histology [TRUTH] study). Am J Cardiol 2013, 111:923-929.

35. PROSPECT Investigators, Stone GW, Maehara A, Lansky AJ, de Bruyne B, Cristea E, Mintz GS, Mehran R, McPherson J, Farhat N, Marso SP, Parise H, Templin B, White R, Zhang Z, Serruys PW: A prospective natural-history study of coronary atherosclerosis. N Engl J Med 2011, 364:226-235

36. Virmani R, Burke AP, Farb A, Kolodgie FD: Pathology of the vulnerable plaque. J Am Coll Cardiol 2006, 47:C13-C18.
37. Kostner GM, Gavish D, Leopold B, Bolzano K, Weintraub MS, Breslow JL: HMG CoA reductase inhibitors lower LDL cholesterol without reducing Lp(a) levels. Circulation 1989, 80:1313-1319.

38. Maher VM, Brown BG, Marcovina SM, Hillger LA, Zhao XQ, Albers JJ: Effects of lowering elevated LDL cholesterol on the cardiovascular risk of lipoprotein(a). JAMA 1995, 274:1771-1774.

39. McKenney JM, Jones PH, Bays HE, Knopp RH, Kashyap ML, Ruoff GE, McGovern ME: Comparative effects on lipid levels of combination therapy with a statin and extended-release niacin or ezetimibe versus a statin alone (the COMPELL study). Atherosclerosis 2007, 192:432-437.

40. Armstrong WW, Schleef J, Thiery J, Muche R, Schuff-Werner P, Eisenhauer T, Seidel D: Effect of HELP-LDL-apheresis on serum concentrations of human lipoprotein(a): kinetic analysis of the post-treatment return to baseline levels. Eur J Clin Invest 1989, 19:235-240.

41. Taylor AJ, Villines TC, Stanek EJ, Devine PJ, Griffen L, Miller M, Weissman NJ, Turco M: Extended-release niacin or ezetimibe and carotid intima-media thickness. N Engl J Med 2009, 361:2113-2122.

42. AIM-HIGH Investigators, Boden WE, Probstfield $J$, Anderson T, Chaitman BR, Desvignes-Nickens P, Koprowicz K, McBride R, Teo K, Weintraub W: Niacin in patients with low HDL cholesterol levels receiving intensive statin therapy. N Engl J Med 2011, 365:2255-2267.

43. Tsimikas S, Bergmark C, Beyer RW, Patel R, Pattison J, Miller E, Juliano J, Witztum $J$ : Temporal increases in plasma markers of oxidized low-density lipoprotein strongly reflect the presence of acute coronary syndromes. J Am Coll Cardiol 2003, 41:360-370.

44. MBewu AD, Durrington PN, Bulleid S, Mackness MI: The immediate effect of streptokinase on serum lipoprotein(a) concentration and the effect of myocardial infarction on serum lipoprotein(a), apolipoproteins $A 1$ and $B$, lipids and C-reactive protein. Atherosclerosis 1993, 103:65-71.

\section{doi:10.1186/1476-511X-13-59}

Cite this article as: Nozue et al:: Lipoprotein(a) is associated with necrotic core progression of non-culprit coronary lesions in statin-treated patients with angina pectoris. Lipids in Health and Disease 2014 13:59.

\section{Submit your next manuscript to BioMed Central and take full advantage of:}

- Convenient online submission

- Thorough peer review

- No space constraints or color figure charges

- Immediate publication on acceptance

- Inclusion in PubMed, CAS, Scopus and Google Scholar

- Research which is freely available for redistribution 